\title{
EVALUATION OF PATTERNS OF IMPACTED THIRD MOLARS AND THEIR ASSOCIATION WITH VITAL STRUCTURES BY RADIOGRAPHIC EXAMINATION
}

\author{
Novaira Waseem, Muhammad Adil Asim*, Ayesha Maqsood*, Muhammad Wajahat Ghafoor**, Noor-Ul-Ain Mirza* \\ Muhammad Omer Khalid* \\ Nishtar Institute of Dentistry, Multan Pakistan, *Rawal Institute of Health Sciences, Islamabad Pakistan, **Foundation University College of \\ Dentistry, Islamabad, Pakistan
}

\begin{abstract}
Objective: To assess the patterns of impacted 3rd molars and their proximity with adjacent vital structures. Study Design: Comparative cross-sectional study.

Place and Duration of Study: Oral \& maxillofacial department of Rawalpindi Dental Hospital, from Oct 2016 to Feb 2018.

Methodology Patient sample size was 956. Orthopantomograms (OPGs) were assessed to determine the presence, patterns of impacted third molars and their relation to maxillary sinus and inferior alveolar canal (IAC) in maxilla and mandible respectively.

Results: Out of 956 Orthopantomograms with $34993^{\text {rd }}$ molars examined, 808 (23.09\%) were impacted. Frequency of impaction was much higher in mandible than maxilla. Out of 527 impacted mandibular $3^{\text {rd }}$ molars $238(45.16 \%)$ were mesio-angular, 370 (70.21\%) had class 1 relation to mandibular ramus \& $266(50.47 \%)$ had level B depth, while among 281 impacted maxillary third molars $134(47.69 \%)$ had vertical angulation and $162(57.65 \%)$ had level B depth. Two hundred and eighty four (53.89\%) impacted mandibular $3^{\text {rd }}$ molars showed relationship with the inferior alveolar canal, out of which 187 (35.48\%) impacted mandibular $3^{\text {rd }}$ molars showed interruption of white line as the most common radiographic finding.

Conclusion: Frequency of impacted third molars was more common in mandible and among females whereas there is significant difference in patterns of impaction among mandible and maxilla. While most impacted teeth have approximation with IAC and maxillary sinus.
\end{abstract}

Keywords: Mandible, Maxilla, Impacted tooth, Maxillary sinus, Third molar.

This is an Open Access article distributed under the terms of the Creative Commons Attribution License (http://creativecommons.org/licenses/by/4.0), which permits unrestricted use, distribution, and reproduction in any medium, provided the original work is properly cited.

\section{INTRODUCTION}

An impacted tooth fails to erupt into the dental arch within the usual range of expected time$^{1}$. A tooth becomes impacted due to malposed adjacent teeth/supernumery teeth, thick cortical bone at alveolar region, intraosseous pathology, or extra soft tissue thickness that hampers its eruption. The third molars are the last teeth to erupt in the oral cavity, so most likely they become impacted due to lack of space. Several theories can explain the pathogenesis of third molar impaction including facial growth retardation, decreased space in the arch, direction of eruption, delayed mineralization of tooth or lack of optimal

Correspondence: Dr Muhammad Wajahat Ghafoor, Department of Oral Pathology, FUCD Rawalpindi Pakistan

Received: 30 Sep 2019; revised received: 28 Dec 2019; accepted: 31 Dec 2019 eruption force ${ }^{2}$. Frequency of impactions in mandible is higher than maxilla due to various anatomical reasons and growth pattern of mandible ${ }^{3}$.

In order to evaluate patterns of third molars Orthopantomogram (OPG) is most commonly used radiographic investigation. 4 We can assess the type of impaction, depth, it's relation to adjacent tooth, maxillary sinus and the Inferior alveolar canal (IAC), to plan the management accordingly. Many studies have shown that the presence of impacted $3^{\text {rd }}$ mandibular molar may lead to various complications including infections, odontogenic cysts/tumors and even fracture at the mandibular angle region ${ }^{1,5}$. Management options include extraction, coronectomy and watch \& wait policy. Prophylactic extraction of impacted third molar though a controversial subject but it has its proponents which suggest that early 
removal of impacted third molars can prevent future complications ${ }^{6}$.

The patterns and prevalence of impacted third molar is quite variable depending upon race, ethnicity, gender and geographical distribution. Due to increased frequency of impacted third molars and associated complications; evaluation of third molars in terms of their angulation, position, depth and relationship with various vital structures is critical for optimal patient management. We examined an extensive number of patients, to find out the patterns of third molars and their association with vital structures, at a tertiary care hospital in northern part of Pakistan.

\section{METHODOLOGY}

This comparative cross-sectional study was conducted at oral \& maxillofacial department of Rawalpindi Dental Hospital from October 2016 to February 2018. Ethics approval was taken from the institute before the start of the study (Ref No: RIHS-REC/035/18).

Consecutive non-probability sampling technique was used. Sample size was calculated with the help of WHO sample size calculator by taking confidence interval of 95\%, anticipated population proportion 0.70, and relative precision of $5 \%$. Inclusion criteria was patients $>20$ years of age with complete root formation of third molars and intact adjacent $2^{\text {nd }}$ molars were included in our study. Exclusion criteria was patients having any pathosis or trauma of jaw, pathological conditions such as down syndrome, cleidocranialdyplasia etc., third molars with incomplete formation of root, patients with missing, grossly carious $2^{\text {nd }}$ and $3^{\text {rd }}$ molars. Confidentiality was maintained while handling patient's data as only principal author and one co-author had access to patient's radiographs. OPG's were analyzed and information including number of impacted third molars, angulation, ramus relation, occlusal relation, proximity to maxillary sinus \& IAC were recorded.

In this study the third molars were considered impacted when they were not fully erupted to their normal functional occlusal level. The angulation of impacted mandibular third molars was defined by Sciller's classification 7 . Impacted third molars were further classified according to Pell \& Gregory's criteria for the depth and relationship with anterior border of ramus ${ }^{8}$.

The radiographic approximation of root apices of mandibular-impacted third molar with IAC was evaluated according to Roods \& Shehab's criteria ${ }^{9}$. Impacted mandibular third molars which were not in approximation with the IAC were labelled as teeth with "no relation".

Association of impacted maxillary $3^{\text {rd }}$ molars with maxillary sinus was evaluated according to modified Archer's classification ${ }^{10}$. Teeth were considered having "no sinus approximation" when the shortest distance between maxillary third molar and the sinus was $\geq 2 \mathrm{~mm}$. If the distance between maxillary third molar and the floor of the sinus was less than $2 \mathrm{~mm}$, it was classified as "maxillary sinus approximation".

Data was analyzed using SPSS-17. Mean \pm SD was calculated for age while frequency and percentages were calculated for categorical variables i.e. gender, patterns of impacted third molars with respect to angulation, depth, anterior border of ramus and their relationship to adjacent vital structures such as IAC (for mandibular teeth) and maxillary sinus (for maxillary teeth). Chi square test was applied to compare the findings of maxillary and mandibular third molars; and male and female subjects. A $p$-value $<0.05$ was considered significant.

\section{RESULTS}

The study sample was composed of 956 out of which 401 (41.9\%) were males and 555 (58.1\%) were females. Overall mean age of the study group was $32.33 \pm 11.232$ years. The mean age of the female subjects was $31.60 \pm 10.52$ years and of the male subjects was $33.33 \pm 12.09$ years.

Total 3499 third molars that fulfilled the inclusion criteria were evaluated, out of which 808 (23.09\%) teeth were impacted, 1966 (56.19\%) were erupted, $725(20.72 \%)$ were missing. Out of 1729 mandibular third molars 885 (51.19\%) 
were erupted, $317(18.33 \%)$ were missing \& 527 $(30.48 \%)$ were impacted. Out of 1770 maxillary 3rd molars evaluated 1081 (61.07\%) were erupted, 408 (23.05\%) were missing and 281 (15.88\%) were impacted. The frequency of impacted mandibular $3^{\text {rd }}$ molars was significantly higher than maxillary impacted 3rd molars. Among total of 808 impacted third molars, $510(63.12 \%)$ were present in females while 298 (36.88\%) were present in males. Furthermore, among all impacted third molars in male subjects, $210(70.47 \%)$ were found in mandible and $88(29.53 \%)$ were in maxilla while in females' out of 510 impacted third molars 317 impacted mandibular 3rd molars while only 3 $(0.57 \%)$ impacted mandibular third molars showed inverted angulation which was the least common type of impaction. Among maxillary $3^{\text {rd }}$ molars the most common angulation was the vertical impaction seen in $134(47.69 \%)$ impacted maxillary $3^{\text {rd }}$ molars while no horizontal impaction was seen in maxilla. Comparison of angulation of impacted third molars among maxilla and mandible revealed $p$-value of $<0.001$ which is highly significant while comparison among all male and female subjects showed $p$-value of 0.034 table-I.

Table-I: Association of impacted mandibular with maxillary third molars in terms of angulation.

\begin{tabular}{|c|c|c|c|c|c|}
\hline \multicolumn{6}{|c|}{ Mandibular 3rd Molar* } \\
\hline Gender ${ }^{* *}$ & $\begin{array}{c}\text { Mesio-Angular } \\
\text { n (\%) }\end{array}$ & $\begin{array}{c}\text { Disto-Angular } \\
\text { n ( } \%)\end{array}$ & $\begin{array}{c}\text { Vertical } \\
\text { n (\%) }\end{array}$ & $\begin{array}{c}\text { Horizontal } \\
\text { n }(\%)\end{array}$ & $\begin{array}{c}\text { Inverted } \\
\text { n (\%) }\end{array}$ \\
\hline Male & $85(40.48 \%)$ & $18(8.57 \%)$ & $53(25.24 \%)$ & $51(24.28 \%)$ & $3(1.43 \%)$ \\
\hline Female & $153(48.26 \%)$ & $18(5.68 \%)$ & $93(29.34 \%)$ & $53(16.72 \%)$ & - \\
\hline \multicolumn{6}{|c|}{ Maxillary 3rd Molar* } \\
\hline Male & $19(21.59 \%)$ & $26(29.55 \%)$ & $43(48.86 \%)$ & - & - \\
\hline Female & $37(19.17 \%)$ & $64(33.16 \%)$ & $91(47.15 \%)$ & - & $1(0.52 \%)$ \\
\hline
\end{tabular}

${ }^{*} p$-value $<0.001,{ }^{* *} p$-value $=0.034$

Table-II: Association of impacted mandibular with maxillary third molars in terms of depth of impaction.

\begin{tabular}{|c|c|c|c|c|c|c|c|}
\hline \multicolumn{4}{|c|}{ Mandibular 3rd Molar* } & \multicolumn{4}{|c|}{ Maxillary 3rd Molar* } \\
\hline Gender** & $\begin{array}{c}\text { Class A } \\
\text { n ( } \%)\end{array}$ & $\begin{array}{c}\text { Class B } \\
\text { n }(\%)\end{array}$ & $\begin{array}{c}\text { Class C } \\
\text { n }(\%)\end{array}$ & Gender** & $\begin{array}{c}\text { Class A } \\
\text { n (\%) }\end{array}$ & $\begin{array}{c}\text { Class B } \\
\text { n }(\%)\end{array}$ & $\begin{array}{c}\text { Class C } \\
\text { n }(\%)\end{array}$ \\
\hline Male & $33(15.71 \%)$ & $105(50 \%)$ & $72(34.29 \%)$ & Male & $3(3.41 \%)$ & $46(52.27 \%)$ & $39(44.32 \%)$ \\
\hline Female & $61(19.24 \%)$ & $161(50.79 \%)$ & $95(29.97 \%)$ & Female & $10(5.18 \%)$ & $116(60.10 \%)$ & $67(34.72 \%)$ \\
\hline
\end{tabular}

Table-III: Association of impacted mandibular third molar with anterior border of ramus.

\begin{tabular}{l|c|c|c|c|}
\hline${ }^{*}$ Gender & Class 1, n (\%) & Class 2, n (\%) & Class 3, n (\%) & p-value \\
\hline Male & $140(66.67 \%)$ & $55(26.19 \%)$ & $15(7.14 \%)$ & 0.018 \\
\hline Female & $230(72.56 \%)$ & $80(25.24 \%)$ & $7(2.20 \%)$ & \\
\hline
\end{tabular}

Table-IV: Association of impacted mandibular third molars with inferior alveolar canal.

\begin{tabular}{|c|c|c|c|c|c|c|c|c|c|}
\hline Gender & II & 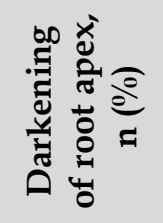 & 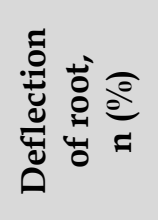 & 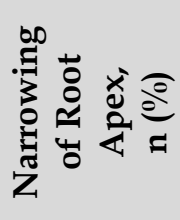 & 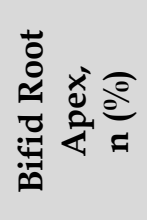 & 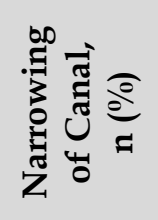 & 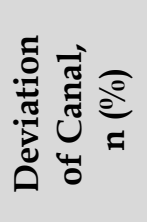 & 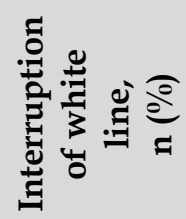 & 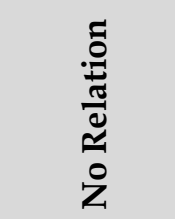 \\
\hline Male & 210 & $36(17.14)$ & $20(9.52)$ & $2(0.95)$ & $3(1.43)$ & $13(6.19)$ & - & $67(31.90)$ & 107 (50.95) \\
\hline Female & 317 & $67(21.14)$ & $13(4.10)$ & $15(4.73)$ & $15(4.73)$ & $22(6.94)$ & - & $120(37.85)$ & $136(42.90)$ \\
\hline
\end{tabular}

$(62.16 \%)$ teeth were found in mandible while just 193 (37.84\%) were in maxilla.

Mesio-angular impaction was the most common angulation which was seen in 238 (45.16\%)
Evaluation of the depth of impacted 3rd molars showed that $266(50.47 \%)$ of impacted mandibular $3^{\text {rd }}$ molars are at class B position. Similarly, in Maxilla 162 (57.65\%) of the impacted 
maxillary $3^{\text {rd }}$ molars were at class $B$ relation, whereas only 3 teeth $(4.63 \%)$ were found impacted at class A position. Furthermore, comparison of depth of impaction among maxillary and mandibular impacted teeth showed highly significant difference ( $p$-value $<0.001)$ while there was no significant difference as far as gender in concerned $(p$-value $=0.269)$ table-II .

Out of 527 impacted mandibular third molars, $370(70.21 \%)$ were in class 1 relation to the anterior boarder of the mandibular ramus, 135 $(25.26 \%)$ in Class 2 and $22(4.17 \%)$ were in Class 3, table-III.

Pre-operative radiographs suggested an involvement of 284 (53.89\%) mandibular impacted 3rd molars with the Inferior alveolar canal (IAC), whereas $243(46.11 \%)$ of the impacted mandibular 3rd molars were found to have no relation with the IAC. Among the teeth with IAC proximity 187 (35.48\%) showed interruption of white line which was the most common sign seen on the radiograph. None of the tooth showed deviation of IAC table-IV.

Finally, when the association of impacted maxillary $3^{\text {rd }}$ molars with the maxillary sinus was studied we found a significantly large number of teeth in close approximation with maxillary sinus. Out of the 281 impacted maxillary $3^{\text {rd }}$ molars, $186(66.19 \%)$ teeth were found to be in approximation with the maxillary sinus, whereas only $95(33.81 \%)$ impacted maxillary $3^{\text {rd }}$ molars were found to have no sinus approximation. Furthermore, there was no significant difference among male and female patients in terms of sinus approximation $(p$-value $=0.057)$.

\section{DISCUSSION}

Impaction of third molar is a common pathological finding of the present era. Maxillary/ mandibular third molars and maxillary cuspids are most frequently impacted. Globally the prevalence of impacted 3rd molars ranges from 16.7\% to $68.6 \%{ }^{6}$. According to our study frequency of impaction was much higher in mandible as compared to maxilla. These results were also supported by Syed et al, colleagues who found $713 \mathrm{imp}-$ acted third molars, in their patients, of which majority were present in mandibular arch ${ }^{11}$. This higher rates of impaction in the lower jaw can be due to the imbalance in pattern of bone resorption and deposition at the mandibular ramus, resulting in decreased mandibular angulation or increased mandibular plane angulation ${ }^{12}$. As most of the facial growth is completed till 18 years of age, the present study was conducted in patients over 20 years of age so that one could differentiate with certainty if third molars will erupt normally or will get impacted.

Kumar et al, \& colleagues described comparatively higher occurrence of impacted third molars among females $(64.9 \%)$ as compared to males $(35.1 \%)^{13}$. Eshghpour et al also supported the above mentioned evidence in their study with $69.8 \%$ of impacted third molars in females ${ }^{14}$. Few studies have also proved increased male proportion of impacted 3rd molars. Kaur et al, and Deshpande et al, showed increased frequency of impacted third molars in males with $54 \%$ \& $65 \%$ respectively 16,17 . Alqahtani et al, \& Taqi et al, also reported higher proportion of male patients with with impacted third molars $(56.7 \%)^{18}$. On the other hand Al-Dajani et al colleagues showed in their study thatthe difference in third molar impaction frequency between males and females were not statistically significant ${ }^{19}$. Osunde et al, showed in his research that impactions of the lower third molar occurred equally in both genders with an approximate ratio of 1:120. Our study showed a significant difference in the occurrence of impacted third molar among male and female subjects, but it can be due to the fact that this study sample had more females $(n=555)$ than males $(n=401)$. Our observations were also in favor with Hellman's theory according to which growth of jaws in males continues for a much longer period, as compared to females, resulting in lesser incidence of arch length discrepancy and ultimately fewer impactions ${ }^{12}$.

Angulation is another parameter for determining the level of difficulty of surgical extraction in case of impacted third molars. In this study mesio-angular impaction was the most common 
pattern in mandible followed by vertical, horizontal and disto-angular patterns. These findings closely relate to study done by Syed et al, which showed that $50.75 \%$ of the patients had mesioangular impaction which constitutes the majority and only $1.4 \%$ of the patients had disto-angular impaction ${ }^{11}$. M Eshghpour also showed that the most common type of tooth angulation was mesioangular $(48.67 \%)^{14}$. Zarrouq et al, his workers also had similar results in their study, $49 \%$ of impacted mandibular third molars showed mesioangular angulation which was the most common type of impaction pattern ${ }^{21}$. Kumar et al, showed contradicting results suggesting vertical impaction $(30.6 \%)$ to be the most common impaction followed by mesio-angular (19.6\%) type ${ }^{13}$. Higher prevalence of mesio-angular impaction might be related to the developmental position of its primordial germ, which is found high in the ramus of mandible having its occlusal surface slanting in a mesial or horizontal inclination. Later, due to gradual growth of mandible the developing crown tends to move in a more upright position. Termination of jaw growth before complete uprighting of the crown will result in entrapment of developing tooth in a mesio-angular position ${ }^{8}$.

In a study by Kumar et al, and colleagues it was shown that in maxilla vertical impaction (46.66\%) accounts for the most common type of impaction followed by disto-angular $(25 \%)$ and mesio-angular inclinations $(20 \%)^{13}$. These results were similar to our findings. Syed et al, also showed similar results, $52 \%$ of the impacted maxillary third molars had vertical impaction in his study ${ }^{11}$. Contrarily, Goyal et al, and co-researchers have shown disto-angular type $(48 \%)$ to bemost common followed by vertical type $(28.4 \%)$ of impaction in maxilla ${ }^{3}$. The higher frequency of vertical impaction in maxilla might be because of the fact that the maxillary third molar develops in vertical relationship in maxillary tuberosity and eventually erupts vertically as the maxillary bone enlarges in a downward-forward direction ${ }^{11}$.

As far as the depth of impaction is concerned in thi study about $50.47 \%$ of mandibular impacted teeth were seen in class B relation, followed by class C (31.69\%) and class A (17.84\%) relation. These results were in agreement with research done by Hatem M, which showed $26.3 \%$ impacted third molars were positioned at level A, $44.7 \%$ were positioned at level B and $29 \%$ were positioned at level $\mathrm{C}^{2}$. Nazir et al, in his study also concluded depth A to be the most common level $(62.8 \%)^{12}$. Yalda et al, in his study showed class $\mathrm{C}$ molar relation to be the most common one $(48.13 \%)$ followed by class A relation $(28.66 \%)^{15}$. We observed similar results in maxilla, as 57.65\% of maxillary impacted $3^{\text {rd }}$ molars were having class B molar relation followed by class C (37.7\%) and class $\mathrm{A}(4.63 \%)$ similar results were seen in Lim et al, study in which most common level for impacted maxillary third molars was class B $(30.2 \%)^{10}$. Hatem et al, in his study concluded class $C$ level is mostly seen in maxillary impacted $3^{\text {rd }}$ molars $(92.2 \%)^{2}$. This can be because the difference in classification methods employed by various researchers.

This study suggested that about $70.21 \%$ of the patients had class 1 relation of impacted mandibular third molars with the anterior boarder of ramus of mandible. Costa et al and his co-researchers also shown similar results in their study as about $50 \%$ of the patients had class 1 relation 22 . Hatem et al, his co-workers proposed class 2 $(72.7 \%)$ to be the most common ramus relation followed by class $1(24.8 \%)$ and class $3(2.5 \%)$ was the least common ramus relationship which was similar to our results².

Seven radiographic predictors proposed by Roods \& Shehab were used to evaluate the proximity of impacted mandibular 3rd molar with IAC. According to our study 53.89\% showed relationship with the IAC while $46.11 \%$ were in no relation with the IAC. Most common radiographic sign noticed in our study was interruption of white line followed by darkening of root apex and the least common predictor observed was deviation of canal which was similar to the results byElkhateeb et al23, Rood et al, \& Shehab et $a l$, in their study concluded that Darkening of the root apex was the most common radiographic predictor, While Yalda et al, \& his co-workers 
fewer have shown deviation of IAC canal to be the most common radiographic sign followed by darkening of root apex ${ }^{15}$.

Proximity of maxillary impacted $3^{\text {rd }}$ molar with maxillary sinus is an important factor to evaluate pre-operatively to prevent possibility of oro-antral perforation. Although there are very few researches that study the association of maxillary sinus with impacted maxillary 3rd molars Fry RR and colleagues 24 found mesiobuccal roots of maxillary first molars present in a much closer approximation to sinus as compared to other posterior teeth. While Lim and colleagues 10 in their study found that most of the impacted maxillary third molars had radiographic approximation to maxillary sinus which is similar to our findings.

\section{CONCLUSION}

The frequency of impacted third molars was much higher in mandible and among female patients. Whereas on comparative analysis of patterns of impaction among maxillary and mandibular third molars, we found a statistically significant difference; as most of the impacted mandibular third molars were at mesioangular, class $1 \mathrm{~B}$ position while maxillary third molars frequently illustrated a vertical, class B pattern. Furthermore, we found that majority of maxillary and mandibular impacted teeth had approximation with maxillary sinus and IAC respectively.

\section{CONFLICT OF INTEREST}

This study has no conflict of interest to be declared by any author.

\section{REFERENCES}

1. Hashemipour MA, Tahmasbi-Arashlow M, Fahimi-Hanzaei F. Incidence of impacted mandibular and maxillary third molars: a radiographic study in a Southeast Iran population. Med Oral Patol Oral Cir Bucal 2013; 18(1): e140-e45.

2. Hatem M, Bugaighis I, Taher EM. Pattern of third molar impac-tion in Libyan population: A retrospective radiographic study. Saudi J Dent Res 2016; 7(1): 7-12.

3. Goyal S, Verma P, Raj SS. Radiographic evaluation of the status of third molars in sriganganagar population-a digital panoramic study. Malays J Med Sci 2016; 23(6): 103-12.

4. Priya PV, Nasyam FA, Ramprasad M, Penumatsa NV, Sandeep. Correlating the clinical assessment of impac-ted mandi-bular third molars with panoramic radiograph and intraoral periap-ical radiograph. J Int Soc Prev Community Dent 2016; 6(Suppl-3): S219-25.
5. Asim MA, Maqsood A, Aslam F, Mujtaba A. Effect of lower third molar status on fracture of mandibular angle and condyle. J Raw Med Coll 2018; 22(2): 152-55.

6. Normando D. Third molars: To extract or not to extract?. Dental Press J Orthod 2015; 20(4): 17-18.

7. Sciller WR. Positional changes in mesioangular impacted mandibular third molars during a year. J Am Dent Aasoc 1975; 99(3): 460-64.

8. Pell GJ, Gregory BT. Impacted mandibular third molars: classification and modified techniques for removal. Dent Digest 1993; 39(1): 330-38.

9. Rood JP, Shehab BA. The radiological prediction of inferior alveolar nerve injury during third molar surgery. Br J Oral Maxillofac Surg Feb 1990; 28(1): 20-25.

10. Lim AA, Wong CW, Allen JC Jr. Maxillary third molar: patterns of impaction and their relation to oroantral perforation. J Oral Maxillofac Surg 2012; 70(5): 1035-39.

11. Syed KB, Zaheer KB, Ibrahim M, Bagi MA, Assiri MA. Preva-lence of impacted molar teeth among saudi population in asir region, Saudi Arabia - a retrospective study of 3 years. J Inter Oral Health 2013; 5(1): 43-47.

12. Nazir A, Akhtar MU, Ali S. Assessment of different patterns of impacted mandibular third molars and their associated patho-logies. J Adv Med Dent Sciences Res 2014; 2(2): 14-22.

13. Kumar SM, Al-Hobeira H, Shaikh S, Siddiqui AA, Syed J, Mian RI, et.al. Distribution of impacted third molars based on gender and patterns of angulation in dental students of the hai'l region, saudiarabia: a panoramic radiographic (opg) study. Int J Contemp Med Res 2017; 4(9): 1829-32.

14. Eshghpour M, Nezadi A, Moradi A, Shamsabadi RM, Rezaei NM, Nejat A. Pattern of mandibular third molar impaction: A cross-sectional study in northeast of Iran. Nig J Clin Pract 2014; 17(6): 673-77.

15. Yalda FA, Al-Refai AS, Al-Mufy KSH. Anatomical study of the relationship of impacted mandibular third molar root apex to inferior alveolar canal in Kurdistan population using orthopantomogram. Zanco J Medl Sci Dec 2017; 21(3): 1859-68.

16. Kaur P. Prevalence of mandibular third molar impaction pattern in a private dental clinic of Sultanpur Lodhi. Int J Health 2015; 3(2): 47-51.

17. Deshpande PV, Guledgud M, Patil K. Proximity of impacted mandibular third molars to the inferior alveolar canal and its radiographic predictors: a panoramic radiographic study. J Maxillofac Oral Surg Jun 2013 12(2): 145-51.

18. Alqahtani ASA, Taqi SA. Prevalence and Pattern of Impaction of Third Molars (Wisdom teeth) among a Saudi Population. J Health Med Nur 2017; 26: 26-42.

19. Al-Dajani M, Abouonq AO, Almohammadi TA, Al-Ruwaili MK, Alswilem RO, Alzoubi IA. A Cohort study of the patterns of third molar impaction in panoramic radiographs in saudi population. The Open Dent J 2017; 11(1): 648-60.

20. Osunde OD. Pattern of impacted mandibular third molars in Calabar, Nigeria. Afr J Med Health Sci 2016; 15(1): 14-17.

21. Zarrouq SA, Karrar MA, Awooda EM. Evaluation of the symptoms and pattern of impaction of mandibular third molars among undergraduate dental students from the university of medical sciences and technology (UMST), Sudan. Sch J Dent Sci 2017; 4(1): 22-26.

22. Costa FW, Fontenele EH, Bezerra TP, Ribeiro TR, Carneiro BG, Soares EC. Correlation between radiographic signs of third molar proximity with inferior alveolar nerve and postoperative occurrence of neurosensory disorders: a prospective, double-blind study. Acta Cir Bras 2013; 28(3): 221-27.

23. Elkhateeb SM, Awad SS. Accuracy of panoramic radiographic predictor signs in the assessment of proximity of impacted third molars with the mandibular canal. J Taibah Uni Med Sci 2018; 13(3): 254-61.

24. Fry RR, Patidar DC, Goyal S, Malhotra A. Proximity of maxillary posterior teeth roots to maxillary sinus and adjacent structures using Denta scan. Indian J Dent 2016; 7(3): 126-130. 